\title{
ANÁLISE DO CLONAZEPAM EM AMOSTRAS DE MEDICAMENTOS REFERÊNCIA E GENÉRICOS POR ESPECTROSCOPIA NO INFRAVERMELHO (FTIR-ATR)
}

\section{Fabrisia de Moraes da Silva ${ }^{1}$ Kumiko Koibuchi Sakane ${ }^{2}$}

\begin{abstract}
Resumo: O Clonazepam é um benzodiazepínico de ação antiansiolítica, anticonvulsiva, relaxante muscular, sedativa e possui propriedades hipnóticas. Seu uso deve ser somente a critério médico. $O$ Clonazepam como qualquer outro benzodiazepínico podem causar dependência e tolerância. Para este estudo propôs-se a analisar qualitativamente por espectroscopia no infravermelho, amostras de medicamentos de referência e genéricos que contenham o princípio ativo clonazepam. Nas amostras avaliadas foram verificadas que a espectroscopia no infravermelho é viável mesmo para amostras com uma concentração pequena de princípio ativo e que os espectros seguem os padrões exigidos pela ANVISA. Palavras-chave: Clonazepam; Espectroscopia no Infravermelho; Benzodiazepínico; Transtornos.
\end{abstract}

\footnotetext{
1 Instituto de Pesquisa e Desenvolvimento/Universidade do Vale do Paraíba, Brasil. E-mail: fab.masilva@gmail.com.

2 Instituto de Pesquisa e Desenvolvimento/Universidade do Vale do Paraíba, Brasil. E-mail: kumiko@univap.br.
} 